\title{
Components of a Year-Long Bridge Program for Minority Engineering Students
}

\author{
Minnie M. McGee, Audeen W. Fentiman \\ The Ohio State University
}

\begin{abstract}
Historical data gathered and assessed as part of the Gateway Engineering Education Coalition program at The Ohio State University indicated that only about 1 in 10 minority engineering students with math placement below college algebra completed a degree in engineering. A significant fraction of incoming minority engineering students, some with excellent high school grades, do not perform well on Ohio State's math placement test and begin their math sequence below college algebra. A year-long series of activities was proposed to improve these students' chances of completing an engineering degree. This paper describes three of those activities and provides some preliminary data on the results. The first activity was a course entitled Strategies for Academic Success. This course was open to all minority engineering students since the skills presented could be of benefit to all, and the older or stronger students could provide some leadership in class. The second activity, a mathematics tutoring session conducted by College of Engineering faculty and staff, provided one-on-one instruction in math along with tips on how to study efficiently. Beginning students who placed below college algebra were asked to participate in this activity. All minority engineering freshmen were invited to participate in the third activity which involved weekly study sessions with individual counseling for students. A separate study session was organized for each math course, from college algebra through differential equations, so students in a given course could work together on assignments. A graduate teaching assistant attended each session. Students who participated in the activities appear to be more successful than those who did not. However, the number of participants was small, and students who could benefit most from the help were often reluctant to attend.
\end{abstract}

\section{Introduction}

Since 1977, Ohio State University's Minority Engineering Program has conducted a summer bridge program called PREFACE. PREFACE is a six-week academic program which serves about 25 students each year. Participants live on campus and spend five full days each week in class or study sessions. They study college-level material in math, chemistry, physics/engineering mechanics, and engineering graphics taught by university instructors and at a pace typical of university classes. Following the academic program, many of the students participate in a six-week internship in industry, putting their skills to use and learning more about what engineers do.

Data from a 10-year Gateway-sponsored study of enrollment and graduation rates of minority engineering students at The Ohio State University shows that the academic performance and graduation rate of PREFACE participants are generally better than those of minority engineering students who have similar backgrounds but who did not have the PREFACE experience. However, students in the PREFACE program are generally ones who begin their math sequence 
in college algebra or higher. Results of the Gateway-sponsored study show that approximately 30 percent of the incoming minority engineering students at Ohio State have math placement test results that place them in college algebra or lower. Programs to help all students develop good study skills and master their course material, particularly math, were required.

During Winter Quarter of 1999, College of Engineering faculty and staff offered a pilot class for minority engineering students called "Strategies for Academic Success." Comparison of the academic performances of students attending the workshop with performances of students who did not attend indicated that the workshop helped students succeed in their courses. As a result, the Minority Engineering Program decided to offer the course the next academic year. Strategies for Academic Success improved students' grade point averages somewhat. However, the students' math grades were still low, and poor performance in math made it difficult for the students to succeed in engineering. A new, year-long, program was instituted to help students with mathematics. In Autumn Quarter 2000, all minority engineering students who placed in Math 104, were invited to participate in the Academic Year Bridge Program. Participants were required to attend a one-hour study session conducted by College of Engineering faculty and staff and designed to provide students with one-on-one tutoring in math. That program was followed Winter and Spring Quarters with a study session and counseling program in which all minority students taking a particular level of math, pre-calculus through differential equations, were invited to meet once a week with a graduate teaching assistant to work on math problems.

This paper describes the Strategies for Academic Success course, the math tutoring program, and the study session and counseling program. It provides information on the content and structure of each program and the results to date.

\section{Strategies for Academic Success}

During Winter Quarter of 1999, the Academic Committee of the National Society of Black Engineers (NSBE) asked their advisors for a workshop to improve the academic performance of their members. In response to that request, College of Engineering faculty and staff developed and offered in Spring Quarter 1999 a course, Strategies for Academic Success. Topics covered included techniques for reading technical material, taking tests, listening, taking notes, and managing time effectively. Collaborative learning and handling racial/gender issues were also covered. Nine NSBE members from various engineering majors and ranks enrolled. They attended eight one-hour sessions and two 2-hour sessions.

After completing the course, participants were expected to be able to apply effective note-taking and time management strategies, to formulate and ask questions that facilitated optimum learning, to set realistic goals for academic success, to accurately access their performance at all times, to improve overall study and test-taking skills, and to deal with issues related to race and gender in an effective manner.

The mean grade point average of the group in Winter Quarter 1999 was 2.31. During the quarter they enrolled in the course their average GPA was 2.71. Subsequently, it reached a high of 3.18 in Winter 2000. While their average GPA dropped some in following quarters, it never dropped as low as the pre-course level. 
For the next academic year, the course was modified and taught by Minority Engineering Program staff. In Autumn and Winter Quarters of 1999 and 2000, certain minority students who were experiencing academic difficulty were invited to enroll. In Spring Quarter other nonminority students were included. Approximately ten students enrolled each quarter. The topics covered were similar to those covered in the initial course. However, the MEP course involved much more student participation.

Both the Autumn and Winter Quarter groups showed improvement during the quarter they were enrolled in the course. The Spring Quarter group's GPA dropped slightly, but has shown marked improvement since then. In general, all groups seem to have benefited from participating in the course. See the chart below.

Average Quarterly GPA of Students Enrolled in Strategies for Academic Success Course

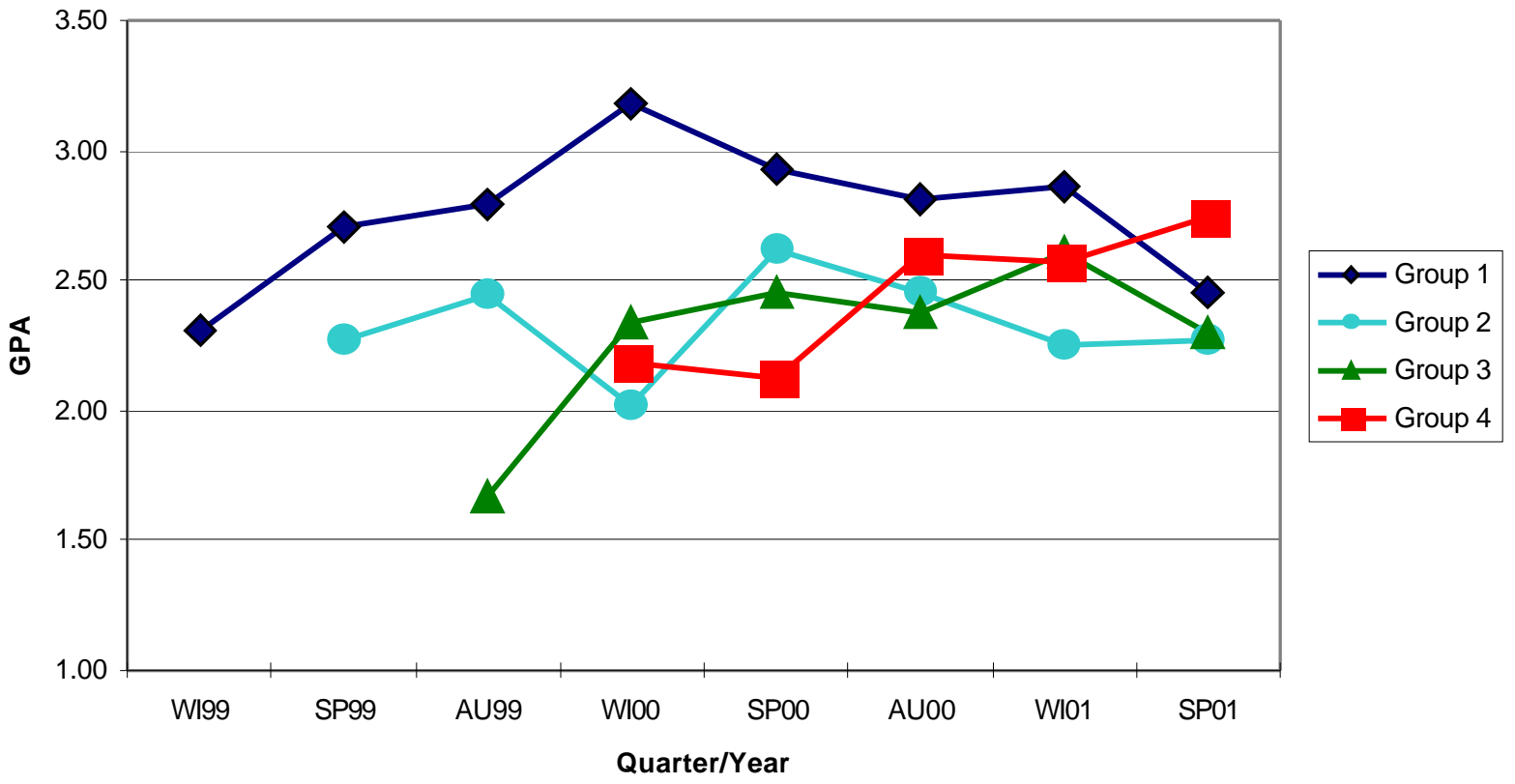

\section{Tutoring for Math 104 Students}

During Autumn Quarter of 2000, the College of Engineering faculty and staff offered a course for Minority engineering students who placed in math 103 or 104. Twenty-two students were identified and invited to participate. The students had varying mathematical backgrounds. A number had taken high school calculus. Only four of these students enrolled in the program.

The course facilitators met with the group weekly in one-hour sessions. The first 10-15 minutes were reserved for discussion. Topics included: developing a personal mission statement, 
selecting or developing an academic skills-building plan, and an ongoing evaluation of the implementation of their chosen plan. Students were encouraged to share successful strategies.

At least two thirds of each session was spent in active problem-solving. The facilitators stressed mastery learning and helped students discover techniques for improving their skills as well as increasing the depth of their understanding.

Participants were expected to develop a conceptual approach to problem solving, to present work neatly and in a well-organized manner with variables clearly defined, and to enhance their understanding by making sketches and diagrams where possible.

Upon completing the program, successful participants were expected to be able to set realistic goals for academic success; to employ proper note-taking and time management strategies; to formulate and ask questions that facilitate optimum learning; to employ proven strategies to study more efficiently and effectively; and to apply techniques learned to improve performance on homework, mid-terms, and final exams.

Hand-outs developed for the Strategies for Academic Success course were made available to the students. They were also encouraged to bring their math text books and other "excellent" math reference texts which they had found to class.

The group was too small to make formal statistical conclusions about the effectiveness of the Academic year bridge program. However, the data does reflect that the students who participated performed better than those who did not attend.

\section{Study Session and Counseling Program}

The Study Session and Counseling Program was implemented Winter Quarter 2001. It was aimed at all minority engineering freshmen ( African American, Hispanic American, and Native American) who entered OSU Autumn Quarter 2000. The students who were invited to participate in the program were enrolled in math pre-calculus (150), the regular calculus series 151, 152, 153 and 254, accelerated calculus (161), elementary analysis II (191), and discrete mathematics (366). The expectation was that this program would enable the students to improve their overall academic performance, especially in math and science courses, to develop selfconfidence and to cultivate more supportive and caring relationships with an overall goal of increasing the retention rate of minority students in engineering at The Ohio State University.

The material covered during the study sessions was related to the specific course work. The objective was to change the student's way of thinking from the paradigm of competition learned in high school to one of collaboration and cooperation used in the upper level engineering courses as well as in industry. The students worked together on their homework assignments and also received help from the facilitator whenever possible. The facilitator was especially effective in keeping the group on task. In addition, he constantly gave advice on studying, learning to manage weekly schedules, preparing for tests and developing effective communication skills. The groups were also encouraged to set up extra study sessions on their own during their free time, particularly on the weekends. The premise was that group interaction would enable the 
students to gain a deeper understanding of difficult concepts while making studying more fun. The expectation was that the students would get together to study more often and in general would increase their study time.

Participants generally showed improvement in mathematics performance. They learned to work productively in collaborative learning situations, to set goals, to prioritize and optimize the use of resources available to them.

The data collected for the winter quarter showed that those who attended these study sessions regularly performed better than those who attended irregularly or did not attend at all. The same observation held for Spring Quarter. This suggests that those who attended these study sessions were more focused and determined to be successful.

The common problem encountered during both quarters was poor attendance. Although regular phone calls and emails were made and sent respectively, the responses fell well short of expectation.

\section{Conclusions}

All of the strategies showed potential for significantly improving the performance of the targeted students. However, a major problem encountered by administrators of all of the activities described in this paper was the challenge of getting eligible students to recognize the need, or to appreciate the rewards for participating. Yet an analysis of the performance of all eligible students verify that some type of intervention strategy to improve the academic performance of a number of engineering freshmen, especially those who place at the lower levels in mathematics, is critical to giving them any reasonable chance of succeeding in the study of engineering.

\section{Acknowledgements}

This project is related to the Gateway Engineering Education Coalition (NSF Award EEC9444246), which is supported in part by the Engineering Education and Centers Division of the National Science Foundation.

\section{BIOGRAPHICAL INFORMATION}

MINNIE M. MCGEE is an Assistant Dean in the College of Engineering At The Ohio State University. She has a B.S. degree in mathematics and chemistry and a M.S. in mathematics. She has been involved in the development and implementation of programs to improve access and performance of ethnic minority engineering students for more than 25 years.

AUDEEN W. FENTIMAN was serving as Associate Dean of Engineering when the work described in this paper was completed. She holds BS and MA degrees in mathematics and MS and Ph.D. degrees in Nuclear Engineering. She has been a leader in the development of a new freshman engineering curriculum at Ohio State and is a former high school math teacher. 